Research Article

\title{
Nonlinear Parametric Resonance Behavior of Cables in a Long Cantilever Bridge for Sightseeing Platform
}

\author{
Zengwei Guo $\mathbb{D}$, Pengfei Zi $\mathbb{D}$, and Xuanbo He \\ State Key Laboratory of Mountain Bridge and Tunnel Engineering, Chongqing Jiaotong University, Chongqing 400074, China \\ Correspondence should be addressed to Zengwei Guo; zengweiguo@cqjtu.edu.cn
}

Received 7 April 2021; Revised 5 September 2021; Accepted 25 September 2021; Published 18 October 2021

Academic Editor: Yaobing Zhao

Copyright (C) 2021 Zengwei Guo et al. This is an open access article distributed under the Creative Commons Attribution License, which permits unrestricted use, distribution, and reproduction in any medium, provided the original work is properly cited.

\begin{abstract}
In order to study the parametric vibration of stayed cables in a long cantilever bridge for a sightseeing platform, nonlinear parametric vibration equations of the stayed cables excited by the vibration of bridge deck and tower are derived. Then, a secondorder differential equation is transformed into a first-order ordinary differential equation, which is solved by using the Runge-Kutta method. A finite element model of cables was also built to verify the solution of the Runge-Kutta method. Then, the inherent dynamic characteristics of the full structure and all the cables with different lengths were analyzed to discuss the potential risk of parametric vibration. The longest and shortest cables were taken as examples to explore their nonlinear vibration performance. The effects of damping ratio, excitation position, and amplitude on cables' nonlinear vibration performance were investigated. The results show that it will be more efficient and convenient to use the Runge-Kutta method to calculate cables' nonlinear vibration amplitude without loss of accuracy. In addition, short cables have more resonance zones compared to long cables. Especially, with the cable length shortening, the dominant frequencies of the dynamic response and its amplitude increase significantly, and the number of resonance zones also increases. However, excessive excitation amplitude will also cause multiple resonance zones in the cable. The parametric analysis results show that it is effective and efficient to mitigate the nonlinear vibration by adjusting the frequency relationship between the bridge and the cables, rather than by increasing the damping ratio.
\end{abstract}

\section{Introduction}

With the development of mountain tourism in China, more and more large-span or long cantilevered sightseeing structures have been widely built on steep cliffs, or in the deep-cutting gorges, such as Zhangjiajie Glass Bridge in Hunan, Aotaoji Sky Suspension Bridge in Chongqing, and Tanxi Mountain Glass Bridge in Shandong. Cable-stayed bridges are popular and widely used sightseeing structures. However, these cable-stayed bridges for sightseeing are usually light and slender, with an attractive appearance. The low stiffness and low damping characteristics of these stayed-cable bridges cause the bridge decks suffer from large vibrations under dynamic loads, such as wind and pedestrians. However, the geometric stiffness of these cables is relatively lower than that of highway or railway bridges, caused by their minor axial forces. If the bridge deck has been excited by wind or other dynamic loads, the axial force in stayed cables may vary periodically. Once the natural frequencies of some stayed cables are similar to the whole structure, these cables may have a high risk of nonlinear parametric vibrations.

Extensive researches have been carried out to analyze the nonlinear dynamic characteristics of cables in highway or railroad bridges. Rega et al. established an approximate model of the three-dimensional nonlinear response of horizontal suspension cables under simple harmonic excitation and investigated the large vibrations of the suspension cables caused by external and parametric excitations [1-3]. Subsequently, Zhao et al. established partial differential equations for in-plane and out-of-plane motions considering temperature effects for horizontal suspension cables and explored the effect of temperature variations on the nonlinear vibration of suspension cables [4]. Macdonald et al. established a three-dimensional nonlinear dynamics model for stayed cables under support displacement 
excitation and studied the resonance zone and resonance amplitude of stayed cables [5-7]. Wu et al. derived the nonlinear in-plane equations of motion for stayed cables [8-10], and Wang investigated the model of continuous tower-cable-deck coupling for cable-stayed bridges [11]. In addition to suspension bridges and cable-stayed bridges, some scholars have also studied the parameter vibration of the temporary cables in cable-arch structures during the cantilever construction phase of arch bridges [12, 13]. However, the pedestrian bridges receive less attention. For the long cantilever bridge for a sightseeing platform, the structure has lighter weight, lower stiffness, minor cable force, and denser cable arrangement. Moreover, these sightseeing platform bridges are usually built on a steep cliff, where the attack angle and wind speed may be larger. These adverse factors may cause the sightseeing platform bridges to suffer from wind-induced vibration. When a cable-stayed bridge for pedestrians has a great number of cables, the axial force of cables may be minor, and these flexible cables may be prone to encounter a higher risk of significant parametric vibration induced by wind-induced vibration of the bridge deck. Therefore, it is necessary to analyze the nonlinear vibration characteristics of the stayed cables of long cantilever bridge for a sightseeing platform in detail.

Generally, the analytical solution of nonlinear vibration equations is difficult to be obtained directly, and it needs to be solved by an approximate method. Rega et al. identified and explored the modes of free vibration of stayed cables both in physical and numerical tests [14]. Subsequently, Sun et al. also conducted a series of nonlinear dynamic tests of stayed cables and found that the multiple internal resonances of cables might cause large-amplitude vibrations of the entire bridge [15]. In addition, Rega et al. [1], Nayfeh et al. [2], and Benedettini et al. [3] adopted the multiple scaled method to analyze the nonlinear vibration of hangers in suspension bridges qualitatively and quantitatively. Subsequently, Warminski et al. also used a multiple-scale method to study the four-degree-of-freedom model of cables, verified the analytical results by numerical simulation results, and found that under a higher excitation amplitude, a multipeak response might appear [16]. Srinil et al. investigated the planar 2:1 resonance of the stayed cables using the multiple-scale method and the Galerkin method and found that the finite element solution agreed well with the response calculated by the approximation of the Galerkin method [17]. Guo et al. introduced Green's functions and proposed a new method to separate the coupled modal frequencies and modal shapes [18]. Marija et al. analyzed the vibration of the cable by the multiple-scale method, validated the analytical results by SAP2000, and found that the resonance zone varied significantly for different angles of the cable [7]. Wang used the Runge-Kutta method to investigate the effect of amplitude and inclination of support's motion on the nonlinear response of stayed cables [19]. The numerical method is a quantitative method to study nonlinear vibration of cables and can be used to obtain the vibration history of cables. Therefore, this paper uses the Runge-Kutta method to analyze the nonlinear vibration of the cables and confirm it with the finite element method.
According to previous studies, when the ratio of the vibration frequency of the bridge deck or tower to the fundamental frequency of the cable is $1: 1$, the primary harmonic resonance of the cable may be excited; when the frequency ratio is $2: 1$, the subharmonic and parametric resonances of cables may be arisen [12]. In addition to the above two main resonance zones, Li discovered that the cable also has three resonance zones when the frequency ratio was around $1: 2,1: 3$, and $2: 3$ [20]. In addition, similar results were obtained by Lei [21]. Later, Nielsen and Sichan studied 1:2 and 2:3 superharmonic resonances of suspension cables and found that excitation amplitude played a critical role on the superharmonic resonance response [22]. Although the phenomenon of multiple resonance zones in low frequency ratio zones has been discovered, the factors that affect the phenomenon and control measures have not been analyzed in detail.

In response to the above issues, this paper takes a long cantilever bridge as an example and analyzes the parametric vibration characteristics of different cables by using the Runge-Kutta method, and the results are compared with finite element method. However, this paper investigates the influence of the damping ratio and excitation frequency on the parametric vibration amplitude of stayed cables, and it examines the effect of cable length and excitation amplitude on the resonance zones of cables. The results of this study can provide guidance for designing the long cantilever bridges for a sightseeing platform and provide suggestions for the vibration suppression of resonance zones of stayed cables.

\section{Parameter Vibration Dynamic Equation of Cable and Its Solution Method}

Stayed cables are distinctly different from horizontal suspended cables. Suspended cables are usually relatively longer, thicker in diameter, heavier in self-weight, and larger in cable force. The frequency matching relationship between bridge deck and cables can be avoided conveniently. However, the stayed cables in cantilever bridges for a sightseeing platform are generally short, with small diameters, and relatively small self-weight and cable force. The number of cables may be so large that it is not possible to avoid all cables' frequencies of being far away from the frequency of the bridge deck, which results in the stayed cable in the pedestrian bridge resonating violently. Therefore, it is necessary to investigate the parametric vibration mechanism of the stayed cables in the long cantilever bridge for sightseeing platforms. Ignoring the bending, torsional, and shear stiffness of the cable, and assuming that the deflection curve of stayed cable under gravity is a parabola, the in-plane vibration differential equation of stayed cable considering the deflection and the geometric nonlinearity caused by large displacements can be expressed as

$$
(H+h) \frac{\partial^{2} v}{\partial x^{2}}+h \frac{\partial^{2} y}{\partial x^{2}}=m \frac{\partial^{2} v}{\partial t^{2}}+c \frac{\partial v}{\partial t},
$$

where $H$ is the chordwise static tension of the cable, $h$ is the chordwise additional dynamic tension of the cable, $m$ is the 


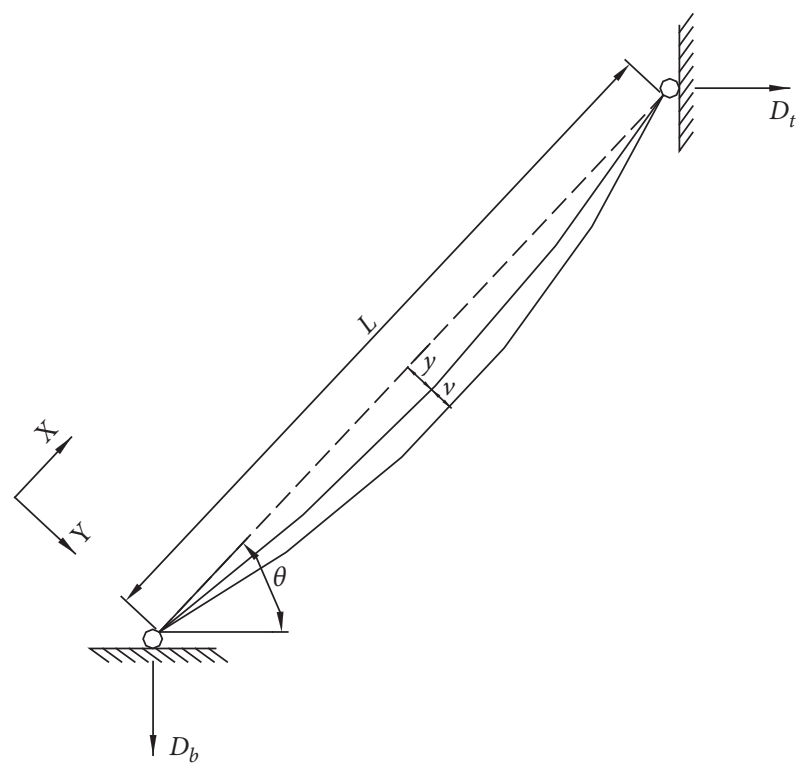

FIgURE 1: Parametric vibration mechanics model of the cable.

mass per unit length of the cable, $\theta$ is the tilt angle of the cable, $s$ is the coordinate of the arc length of the cable, $v$ is the vibration displacement in the $Y$ direction (as shown in Figure 1), $y$ is the deflection by the self-weight of the cable in the $Y$ direction, and $c$ is the damping coefficient per unit length of the cable.

According to the existing research data in the literature [23], the vibration predominated in the first-order mode is most likely to be excited by the displacement excitation at the end of the cable. Therefore, only taking the first-order mode of the cable into account, a continuous system can be transformed into a single degree-of-freedom system by the modal superposition method. Then the Galerkin method is adopted [10], and the shape function is assumed as $\sin (\pi x)$ $L$ ). The vibration displacement in the $Y$ direction at any point of the cable can be obtained by the following equation:

$$
v(x, t)=V(t) \sin \left(\frac{\pi x}{L}\right)+D_{b} \cos \theta\left(1-\frac{x}{L}\right)+D_{t} \frac{x}{L} \sin \theta .
$$

Substituting the equation (2) into equation (1), multiplying both sides by the shape function $\sin (\pi x / L)$, and integrating in the range of 0 to $L$, the differential equations for the nonlinear parametric vibration of stayed cables excited by end displacement at the bridge deck and tower excitation can be derived. The differential equations derived in this paper are essentially the same as that derived in the literature [10]. In the literature [10], the displacement excitations at both ends of the cable were the relative displacement at the deck, while in this paper, the displacement excitations are separated into deck vibration and tower vibration:

$$
\begin{aligned}
V^{\prime \prime} & +2 \omega_{1} \xi V^{\prime}+\left(I_{1}+I_{2}+I_{3}\right) V+I_{4} V^{2} \\
& +I_{5} V^{3}+\beta_{1}+\beta_{2}+\beta_{3}=0
\end{aligned}
$$

where

$$
\begin{aligned}
& \frac{c}{m}=2 \omega_{1} \xi \\
& I_{1}=\frac{\pi^{2} H}{m L^{2}}\left[\alpha_{1}+\frac{8 \lambda^{2}}{\pi^{4}} \alpha_{2}\right]=\omega_{0}^{2} \alpha_{3} ; \\
& \omega_{0}^{2}=\frac{\pi^{2} H}{m L^{2}} ; \\
& \omega_{1}=\sqrt{I_{1}} ; \\
& I_{2}=\frac{\pi^{2} E A}{m L^{2} L_{e}}\left(D_{b} \sin \theta+D_{t} \cos \theta\right) \alpha_{1} \\
& I_{3}=\frac{\pi^{2} E A}{2 m L^{3} L_{e}}\left(D_{b} \cos \theta-D_{t} \sin \theta\right)^{2} \alpha_{1} \text {; } \\
& I_{4}=\frac{4 \pi d E A}{m L^{4} L_{e}}\left(6 L-\frac{80 d^{2}}{3 L}+\frac{192 d^{2}}{\pi^{2} L}\right) \\
& I_{5}=\frac{\pi^{4} E A}{4 m L^{3} L_{e}} \alpha_{1} \\
& \beta_{1}=\frac{32 d E A}{\pi m L^{2} L_{e}}\left(D_{b} \sin \theta+D_{t} \cos \theta\right) \alpha_{2} \\
& \beta_{2}=\frac{2\left(\ddot{D}_{d} \cos \theta-\ddot{D}_{t} \sin \theta\right)}{\pi} ; \\
& \beta_{3}=\frac{16 d E A}{\pi m L^{3} L_{e}}\left(D_{b} \cos \theta-D_{t} \sin \theta\right)^{2} \alpha_{2} ; \\
& \alpha_{1}=1-\frac{8 d^{2}}{3 L^{2}}+\frac{16 d^{2}}{L^{2} \pi^{2}} \\
& \alpha_{2}=1-\frac{8 d^{2}}{L^{2}}+\frac{64 d^{2}}{L^{2} \pi^{2}} \\
& \alpha_{3}=\alpha_{1}+\frac{8 \lambda^{2}}{\pi^{4}} \alpha_{2} \\
& L_{e} \approx L\left(1+\frac{8 d^{2}}{L^{2}}\right) \\
& d=\frac{m g L^{2} \cos \theta}{8 H} \\
& \lambda^{2}=\frac{(m g L \cos \theta / H)^{2} L}{\left(H L_{e} / E A\right)},
\end{aligned}
$$

where $L$ is the chord length of the cable; $d$ is the midspan deflection; $V$ is the transverse vibration displacement at the midspan of the cable; $V^{\prime}$ and $V^{\prime \prime}$ are the first-order and second-order partial derivative of $V$ with respect to time $t$, respectively; $\xi$ is the first-order modal damping ratio of the 
cable; $\omega_{0}$ is the fundamental frequency of the cable without considering the influence of the cable deflection; $\omega_{1}$ is the fundamental frequency of the cable considering the influence of the cable deflection parameter and the initial equilibrium position; $\alpha_{3}$ is the fundamental frequency correction factor in the cable vibration model; $\alpha_{1}$ and $\alpha_{2}$ are the parameters influenced by the initial equilibrium position of the cable, respectively; $\lambda^{2}$ is the deflection parameter of the cable, called the Irvine parameter; $I_{2}$ and $I_{3}$ are the parametric vibration terms of the cable, respectively; $I_{4}$ and $I_{5}$ are the nonlinear terms caused by deflection and large vibration, respectively; $\beta_{1}, \beta_{2}$, and $\beta_{3}$ are the forced vibration terms of the cable, respectively; and $D_{b}$ and $D_{t}$ are the displacement response of the cable caused by the vibration of the bridge deck and tower excited by pedestrian loads or wind loads, respectively.

Equation (3) is a second-order differential equation of transverse vibration displacement at midspan of cables $(V)$ against time. For the convenience of solution, this paper introduces an intermediate variable $z=V^{\prime}$ to reduce equation (3) into the following first-order equations:

$$
\left\{\begin{array}{l}
V^{\prime}=z \\
V\left(t_{0}\right)=V_{0} \\
z^{\prime}=f(t, V, z)=-\left[2 \omega_{1} \xi z+\left(I_{1}+I_{2}+I_{3}\right) V+I_{4} V^{2}+I_{5} V^{3}+\beta_{1}+\beta_{2}+\beta_{3}\right] \\
z\left(t_{0}\right)=V_{0}^{\prime} .
\end{array}\right.
$$

The Runge-Kutta method is a typically used single-step solution algorithm for initial value problems of first-order differential equations, which is used to solve the differential equation for the nonlinear parametric vibration of the stayed cable. In the Runge-Kutta method, the value of the displacement $V_{i+1}$ at midspan of the cable at time $i+1$ can be determined by multiplying $V_{i}$ at moment $i$ and the associate slope at moment $i$. In the time interval $\left[t_{i}, t_{i+1}\right]$, the predicting formula of 4th-order Runge-Kutta is

$$
\left\{\begin{array}{l}
V_{i+1}=V_{i}+\frac{m}{6}\left(K_{1}+2 K_{2}+2 K_{3}+K_{4}\right), \\
z_{i+1}=z_{i}+\frac{m}{6}\left(L_{1}+2 L_{2}+2 L_{3}+L_{4}\right),
\end{array}\right.
$$

where $K$ and $L$ are the slopes of $V(t)$ and $z(t)$ at $t$, respectively; the subscripts 1 and 4 denote the scopes at time $t_{i}$ and time $t_{i+1}$; and subscripts 2 and 3 denote the initial and predicting slopes at $t_{i}+\left(t_{i+1}-t_{i}\right) / 2$, respectively. The scopes associate with time $t_{i+1}$ and $t_{i}+\left(t_{i+1}-t_{i}\right) / 2$ could be determined by the following equation:

$$
\left\{\begin{array}{l}
K_{1}=z_{i}, \\
K_{2}=z_{i}+\frac{m}{2} L_{1}, \\
K_{3}=z_{i}+\frac{m}{2} L_{2}, \\
K_{4}=z_{i}+m L_{3}, \\
L_{1}=f\left(t_{i}, V_{i}, z_{i}\right), \\
L_{2}=f\left(t_{i}+\frac{m}{2}, V_{i}+\frac{m}{2} K_{1}, z_{i}+\frac{m}{2} L_{1}\right), \\
L_{3}=f\left(t_{i}+\frac{m}{2}, V_{i}+\frac{m}{2} K_{2}, z_{i}+\frac{m}{2} L_{2}\right), \\
L_{4}=f\left(t_{i}+m, V_{i}+m K_{3}, z_{i}+m L_{3}\right),
\end{array}\right.
$$

where $m=t_{i+1}-t_{i}$ is the calculation step. Then, this paper eliminates $K_{1}, K_{2}, K_{3}$, and $K_{4}$ from the joint equations (6) and (7) and obtains the following equation, by which the solution procedure was programmed:

$$
\left\{\begin{array}{l}
V_{i+1}=V_{i}+m z_{i}+\frac{m^{2}}{6}\left(L_{1}+L_{2}+L_{3}\right), \\
z_{i+1}=z_{i}+\frac{m}{6}\left(L_{1}+2 L_{2}+2 L_{3}+L_{4}\right), \\
L_{1}=f\left(t_{i}, V_{i}, z_{i}\right) \\
L_{2}=f\left(t_{i}+\frac{m}{2}, V_{i}+\frac{m}{2} z_{i}, z_{i}+\frac{m}{2} L_{1}\right) \\
L_{3}=f\left(t_{i}+\frac{m}{2}, V_{i}+\frac{m}{2} z_{i}+\frac{m^{2}}{4} L_{1}, z_{i}+\frac{m}{2} L_{2}\right) \\
L_{4}=f\left(t_{i}+m, V_{i}+m z_{i}+\frac{m^{2}}{2} L_{2}, z_{i}+m L_{3}\right)
\end{array}\right.
$$

\section{Comparison of the Runge-Kutta Method and Finite Element Method}

To verify the response of parametric vibration of stayed cable by the proposed Runge-Kutta method, a cantilevered bridge for a sightseeing platform was taken as an example. This viewing platform will be constructed on the edge of the cliff at an altitude of $1500 \mathrm{~m}$, with a cantilevered length of $70 \mathrm{~m}$, and a width of $23.4 \mathrm{~m}$, which will become the world's longest glass viewing bridge with cantilevered cables after completion. This paper selects the longest and shortest cables in the bridge (as shown in Figure 2) to conduct the verification of analysis results by the Runge-Kutta method. The short 


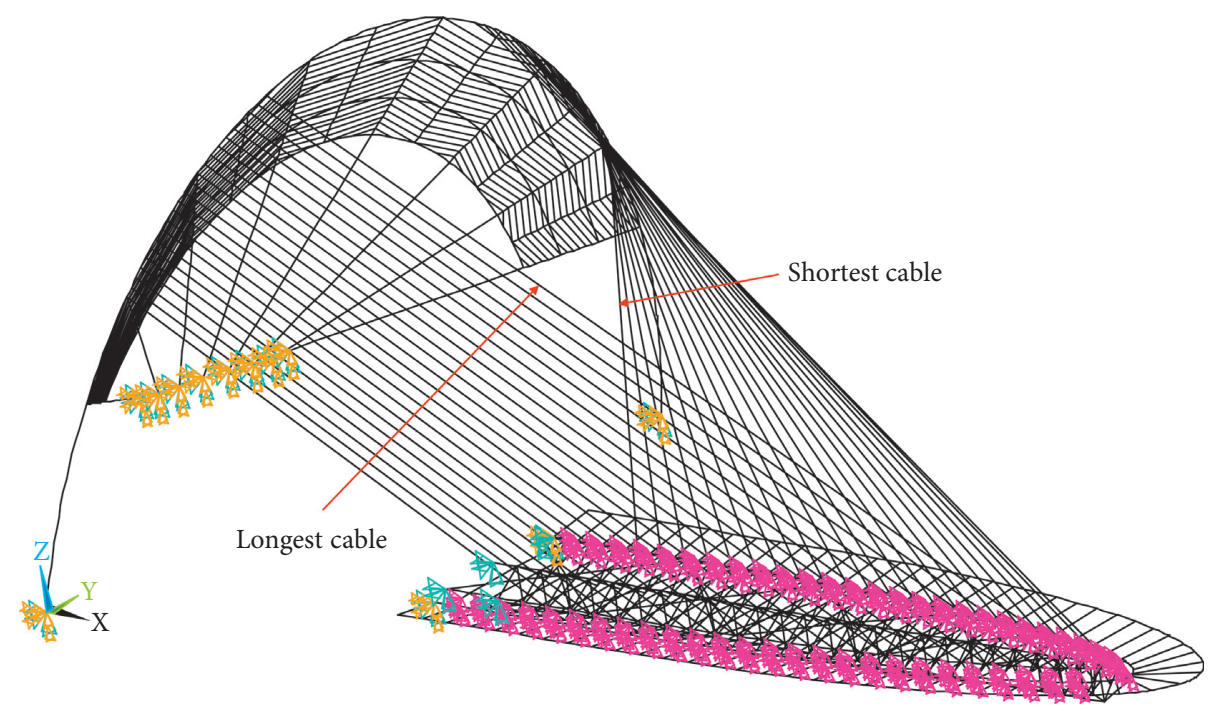

FIgURE 2: Finite element model of the cantilevered bridge for the sightseeing platform.

cable had a length of $30.6 \mathrm{~m}$, an inclination angle of $67.2^{\circ}$, and an initial tension of $230.2 \mathrm{kN}$. The longer cable was $77.5 \mathrm{~m}$ in length, an inclination angle of $33.1^{\circ}$, and an initial force of $347.5 \mathrm{kN}$. The gravity deflections were $0.033 \mathrm{~m}$ and $0.302 \mathrm{~m}$ corresponding to the shortest and longest cables. The cross-sectional area and elasticity modulus of both cables are set to $0.00212 \mathrm{~m}^{2}$ and $160 \mathrm{GPa}$. In addition, in order to analyze whether the cables meet the conditions for resonance, it is necessary to analyze the inherent natural frequencies of stayed cables and the full structure, and the results are plotted in Figure 3. The cables that may have primary harmonic, the subharmonic, and parametric resonances can be judged from Figure 3.

In Figure 3, it is obvious that there are about half of the cables whose natural frequencies are close to or even equal to certain frequency of full structure. Specifically, 1\#, 26\#, and 29-31\# cables have a higher probability of the primary harmonic resonance, as their frequencies are close to the natural frequency of 1 st-order and 2 nd-order models of full structure, respectively; 1\# 5\#, 7\# 11\#, 24\#, 25\#, 27\#, 28\#, $31 \# \sim 33 \#$, and 35\# 38\# cables have a higher probability of the subharmonic and parametric resonances, as their frequencies are about one half of the structure's 3rd-order, 4thorder, 5th-order, 6th-order, and 7th-order models.

LINK180 elements were used to build the finite element model of the stayed cable. The cable with $77.5 \mathrm{~m}$ in length was meshed into 20 elements (as shown in Figure 4). The static axial force was equivalent to initial strain. The boundary condition at the upper end of the cable was set to be articulated, and the horizontal displacement at the lower end of the cable was constrained. The fundamental in-plane frequency calculated by ANSYS was $0.924 \mathrm{~Hz}$, with an error of about $3.5 \%$ from the theoretical result. A harmonic displacement excitation was applied in the vertical direction to simulate the vibration of the bridge deck. The amplitude was denoted as $D_{b}$, and the vertical displacement of the bridge deck was set to two conditions, namely, $D_{b}=0.03 \mathrm{sin}$ $\left(\omega_{1} t\right)$ for working condition I; $D_{b}=0.03 \sin \left(2 \omega_{1} t\right)$ for

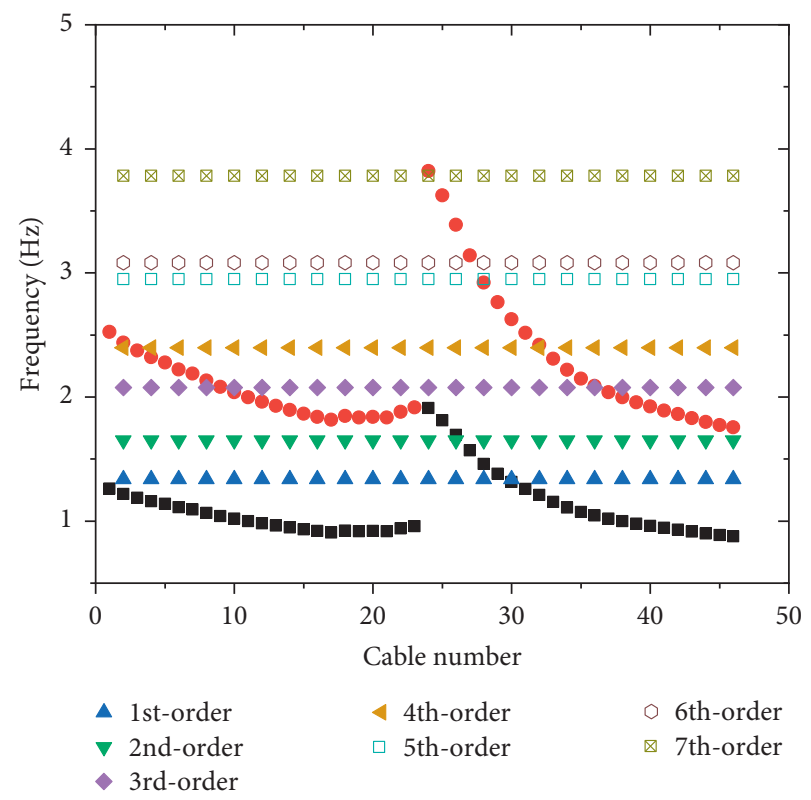

Figure 3: The relationship between the whole bridge vibration mode and the cable vibration mode (black squares and red solid circles are once and twice fundamental frequency of the cable, respectively, and the horizontal line is the inherent frequency of the bridge).

working condition II, in which $\omega_{1}$ was the in-plane fundamental frequency of the cable. The harmonic exciting displacement whose frequency was equal to the in-plane fundamental frequency for working condition I, which was defined as primary harmonic resonance of the cable; while the frequency of harmonic exciting displacement was twice of the in-plane fundamental frequency for working condition II, which was defined as subharmonic and parametric resonances of cables. The initial displacement, velocity and acceleration were all set to zero. Full transient dynamic analysis was conducted to calculate the dynamic response of the cable. The total time was set to $1000 \mathrm{~s}$ and was divided 


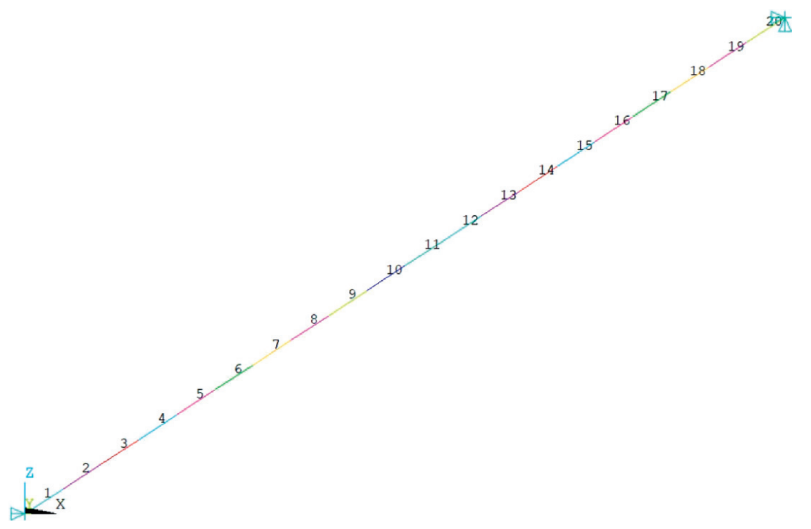

FIgURE 4: The finite element model and element numbering diagram of the cable.

into 10,000 load steps, in which there were 5000 substeps. Dynamic response at midspan of stayed cable was calculated by both transient analysis in ANSYS and the Runge-Kutta method and contrasted in Figure 5. When using the Runge-Kutta method to calculate the nonlinear parametric vibrations, the initial condition was also set to zero, which implies that the cable remains static just at the moment that the ending excitation starts.

As shown in Figure 5, the time history of the steady response of the stayed cable calculated by the Runge-Kutta method accorded well with the ANSYS calculation results, which confirms the correctness of the Runge-Kutta method. However, the required time calculated by ANSYS was about 5 hours, while the required time calculated by using the Runge-Kutta method was less than 1 minute. However, the phenomenon of beats could be observed directly from the initial history of displacements at the midspan of the stayed cable for both working conditions. However, the subharmonic and parametric resonances required a longer time to reach its steady response than that of the primary harmonic resonance; but the steady response of the subharmonic and parametric resonances was slightly larger than that of the primary harmonic resonance, which were ten times of excitation amplitude. Hence, the subharmonic and parametric resonances should also receive the same attention as the forced resonance during the design. Moreover, the displacement response was not completely symmetrical about its equilibrium position due to the influence of the self-weight deflection of the cable.

\section{Characteristics of Parametric Vibration}

4.1. Effect of Initial Condition. According to the existing study [13], the stable response of the cable's nonlinear vibration has an obvious multivalued phenomenon in a certain frequency range. This multivalued phenomenon is usually analyzed by the multiple time-scale method or harmonic balance method, as some stable solutions are difficult to acquire by using the numerical method. The deficiency of the numerical method is mainly caused by the dependence of calculation results on the initial conditions. In order to explain the effect of initial conditions on the stable response of the cable's parameter vibration, subharmonic and parametric resonance zones of $77.5 \mathrm{~m}$ cable are taken as an example, and the damping ratio is set to $0.1 \%$. The initial conditions are varied from $0 \mathrm{~m}$ to $0.8 \mathrm{~m}$. The stable vibration amplitude at the midspan of the cable under different frequency ratios are plotted in Figure 6.

As shown in Figure 6, below the frequency ratio of 2.1, the results under different initial conditions are consistent. Within a certain range above the frequency ratio of 2.1, the stable amplitude of the cable is not unique and dependent on the initial conditions. Different initial conditions will lead to different stable solutions of the cable, which is mainly due to the influence of the 3rd-order nonlinear term in the vibration equation. The response curves exhibit hardening characteristics and bend in the positive direction. Although it is difficult to obtain the largest stable solutions with an initial condition, the resonance zones' number is not affected by the initial conditions. The main focus of this paper is to discuss the effect of cable length on the number of resonance zones and to analyze the characteristics of $2: 3$ superharmonic resonance. Therefore, the initial conditions are set to zero in subsequent numerical analysis, and these large response solutions are not displayed further.

4.2. Characteristics of Parametric Vibration. In order to observe how the excitation frequency and damping ratio affect the peak amplitude of parametric vibration, a sinusoidal displacement exciting with the amplitude of $0.03 \mathrm{~m}$ was applied to one tip of the stayed cable with lengths of $77.5 \mathrm{~m}$ and $30.6 \mathrm{~m}$, respectively. The exciting displacement at the end near the bridge deck was denoted by working condition III, and the excitation at the tower point was defined as working condition IV. The damping ratios are taken as $0.1 \%, 0.3 \%, 0.5 \%$, and $1.0 \%$, respectively. According to the existing research data in the literature [20], large vibration resonance may occur in the cables when the frequency ratios $\left(\omega_{b} / \omega_{1}\right.$ and $\left.\omega_{t} / \omega_{1}\right)$ are around $1: 3,2: 31: 2$, $1: 1$, or $2: 1$, respectively. Therefore, near the above resonance zones, the peak amplitudes at the midspan of the cable at some specific frequencies are plotted in Figure 7.

As shown in Figure 7, the amplitudes of the primary harmonic resonance or subharmonic and parametric resonances excited by tower's vibration are not equal to the 


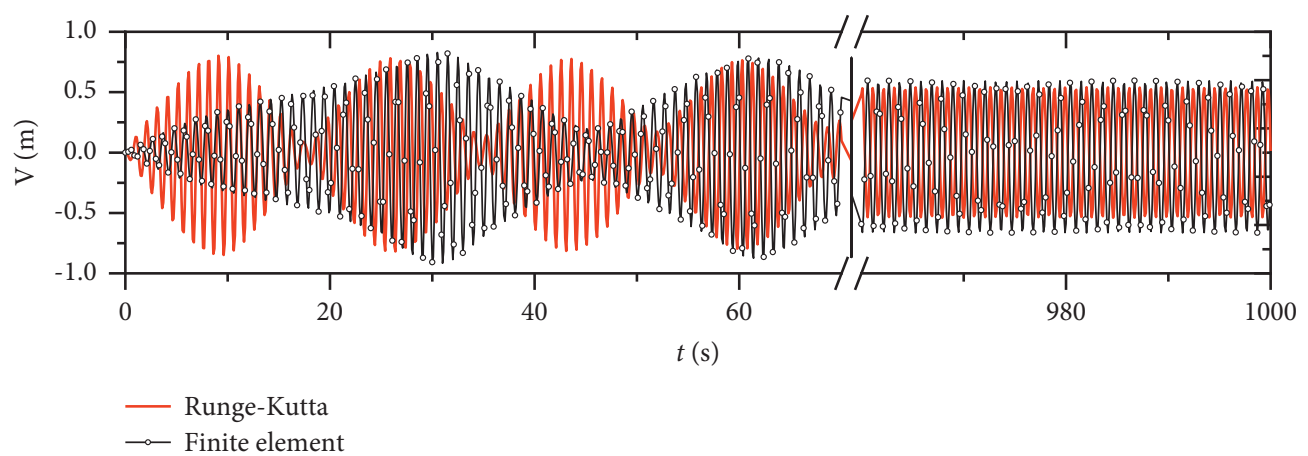

(a)

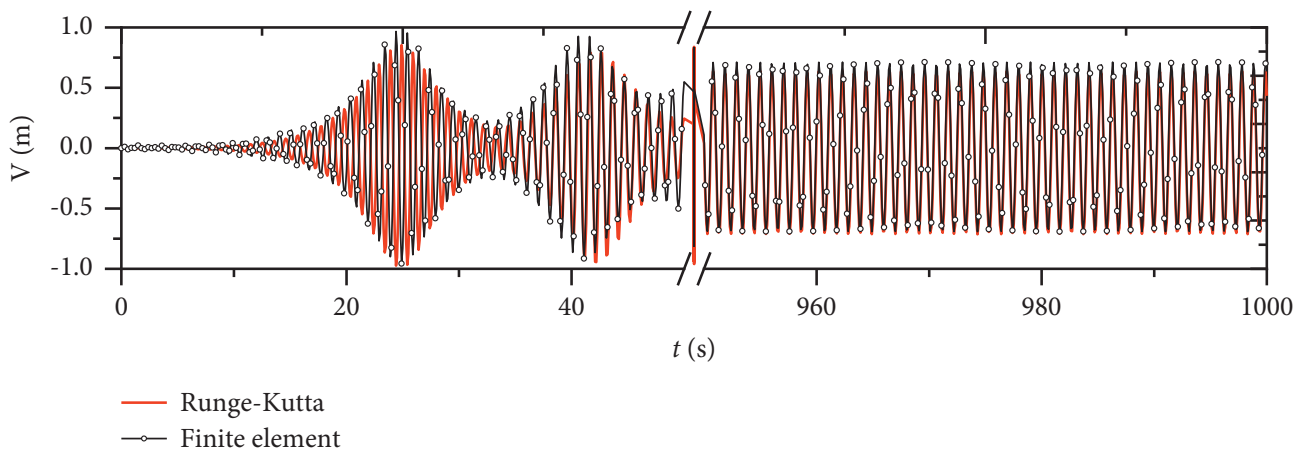

(b)

Figure 5: Dynamic response at midspan of the stayed cable. (a) Primary harmonic resonance (working condition I). (b) Subharmonic and parametric resonances (working condition II).

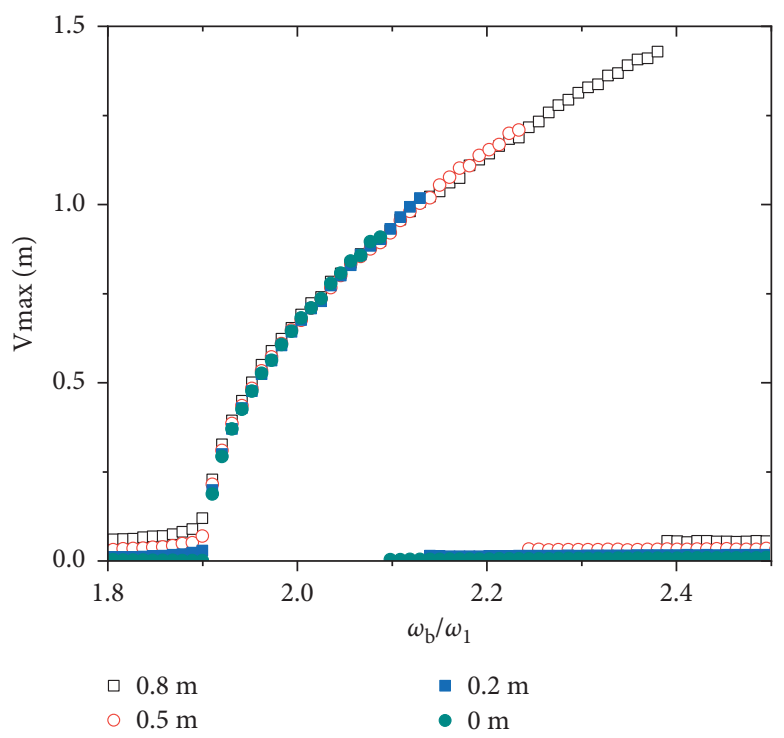

FIgURE 6: The vibration response at midspan of the cable under different initial conditions.

vibration amplitude excited by deck's vibration, even though the excitation amplitudes of the bridge deck and tower are identical. It can be explained by their inclination angles that may lead to the axial component accounting for different proportions of exciting displacements for the two cables. Due to the nonlinear effects in the subharmonic and parametric resonances, it is evident that the maximum amplitudes of the subharmonic and parametric resonances do not occur exactly at a frequency ratio of 2.0 , but the exciting frequency associated with the maximum amplitude is slightly larger than twice of the fundamental frequency. In addition, by comparing the cable amplitude under different 


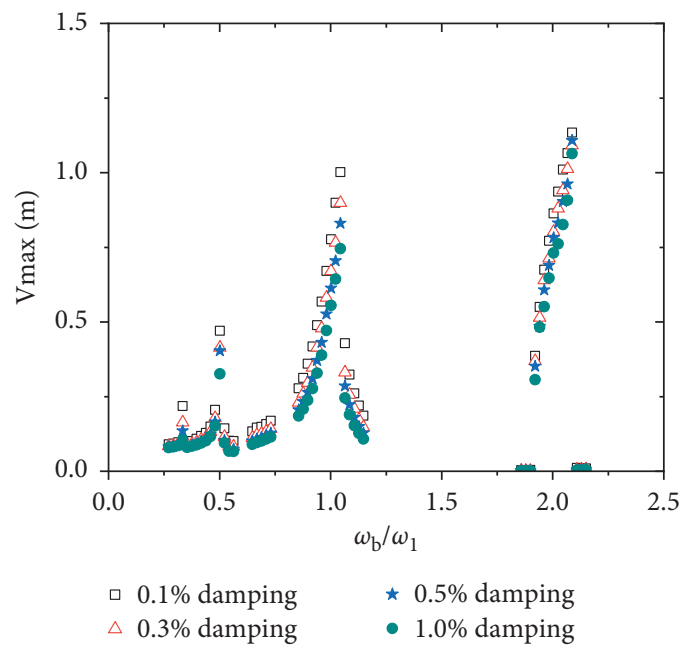

(a)

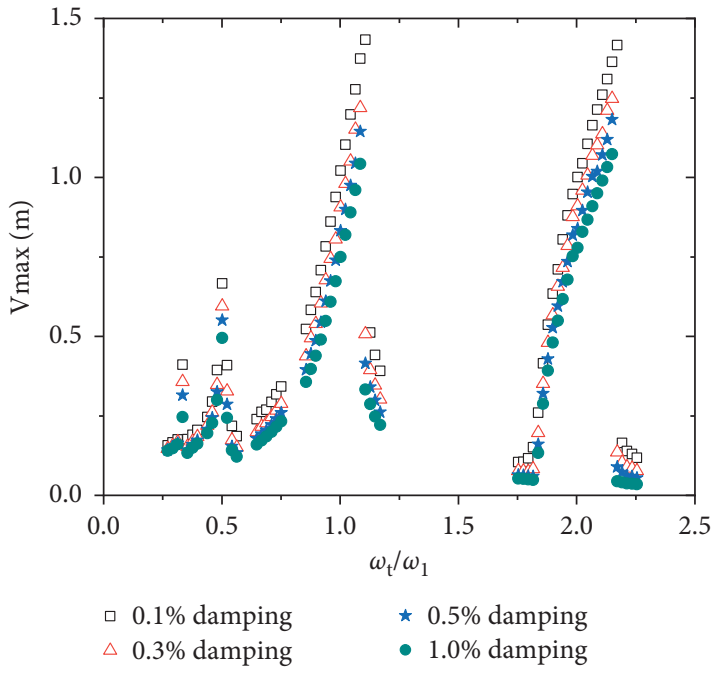

(b)

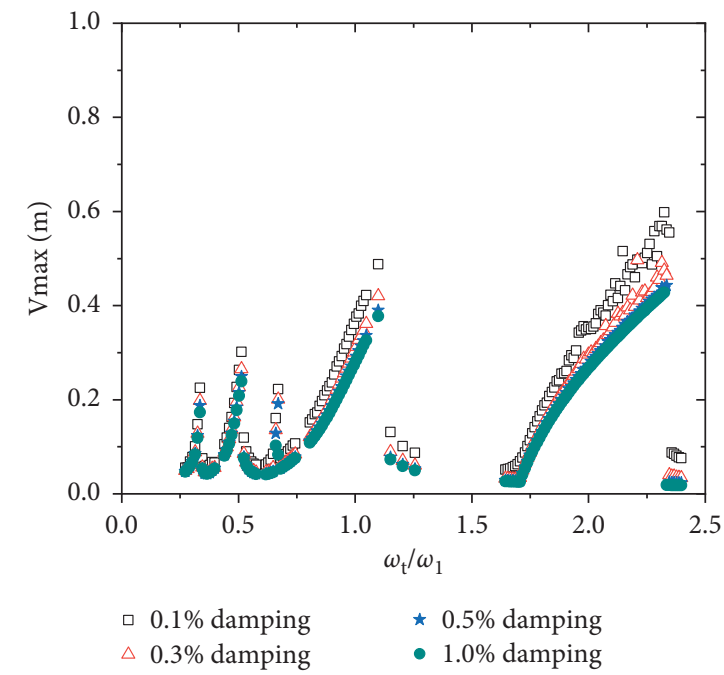

(c)

Figure 7: The peak amplitude at midspan of the cable. (a) Cable with a length of $77.5 \mathrm{~m}$ (working condition III). (b) Cable with a length of $77.5 \mathrm{~m}$ (working condition IV). (c) Cable with a length of $30.6 \mathrm{~m}$ (working condition IV).

damping ratios, it can be found that the damping ratio has little effect on the amplitude of the subharmonic and parametric resonances, which means that it is difficult to suppress the subharmonic and parametric resonances by increasing the damping ratio once it is excited already. However, it is effective and efficient to adjust the inherent frequency of the cable by installing some auxiliary cables. The reason for this is that the subharmonic and parametric resonances of the cable are mainly affected by the nonlinear relationship of the system.

In particular, Figure 7 indicates that there are totally four resonance zones for the cable with $77.5 \mathrm{~m}$ in length, and the ratios of the excitation frequency to the in-plane fundamental frequency of the stayed cable are close to $1: 3$, $1: 2,1: 1$, and $2: 1$, respectively, which is consistent with the results in the literature [20]. However, there are five resonance zones in the short cable with a length of $30.6 \mathrm{~m}$, which is significantly different from the longer cable with a length of $77.5 \mathrm{~m}$.

In order to further analyze the nonlinear parametric vibration characteristics of cables, the phase plane diagrams related to the displacement at the middle span of the cable with $77.5 \mathrm{~m}$ in length were calculated and are shown in Figure 8, And the peak amplitudes at the midspan of the cable with different excitation amplitudes and different damping ratios are given in Figure 9.

As shown in Figure 8, when a cable reaches the stage of steady-state periodic motion (as shown in Figures 8(b) and $8(c)$ ), its phase plane diagrams become a concentric ellipse, which indicates that no energy has been dissipated in the vibration process and the motion of the system can be viewed as a nondecaying equal-amplitude oscillation. For the case of $\omega_{b} / \omega_{1} \approx 0.502$ and 1.04 , there is only one Poincare section point (red point) in the phase plane diagrams. 


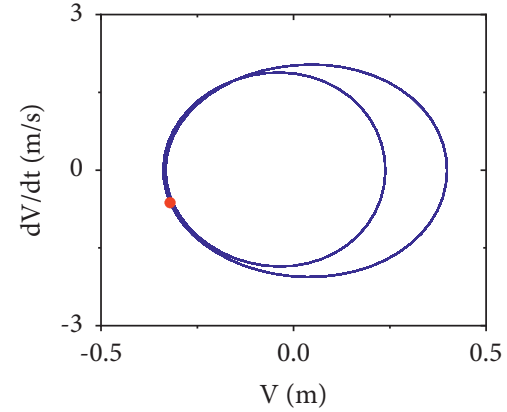

(a)

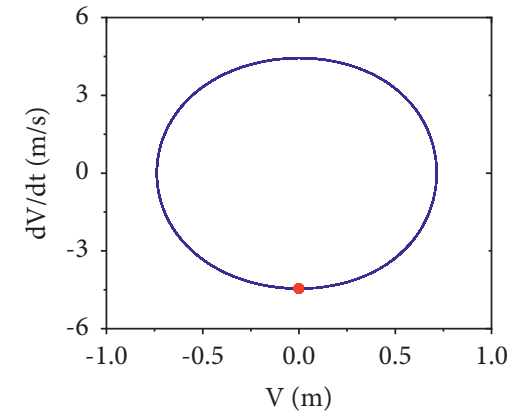

(b)

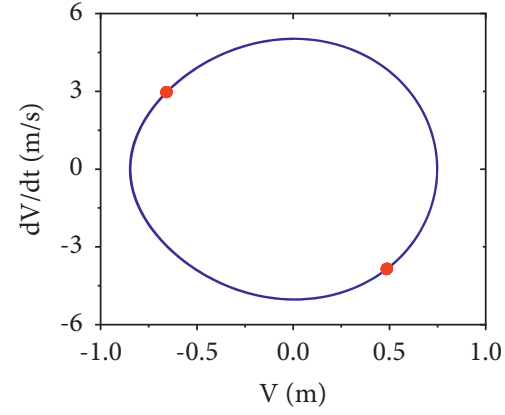

(c)

Figure 8: The phase plane diagrams and Poincare sections (red point) of the cable (working condition III). (a) $\omega_{b} / \omega_{1} \approx 0.502$. (b) $\omega_{b} /$ $\omega_{1} \approx 1.04$. (c) $\omega_{b} / \omega_{1} \approx 2.04$.

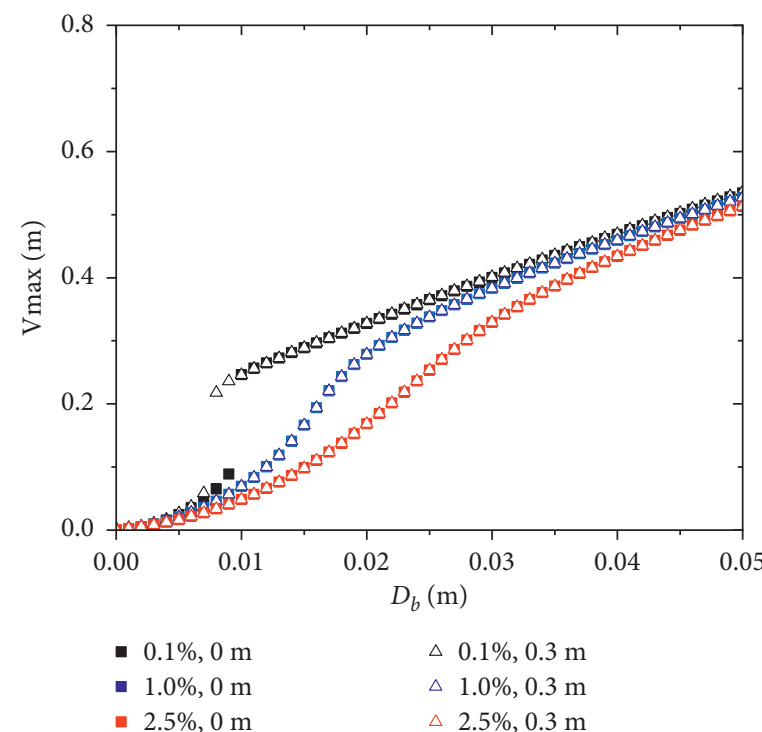

(a)

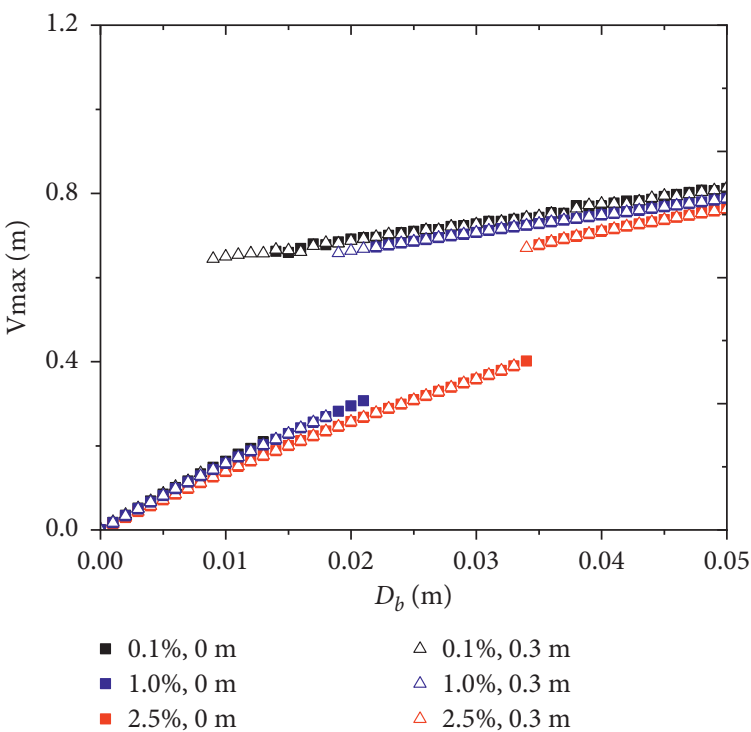

(b)

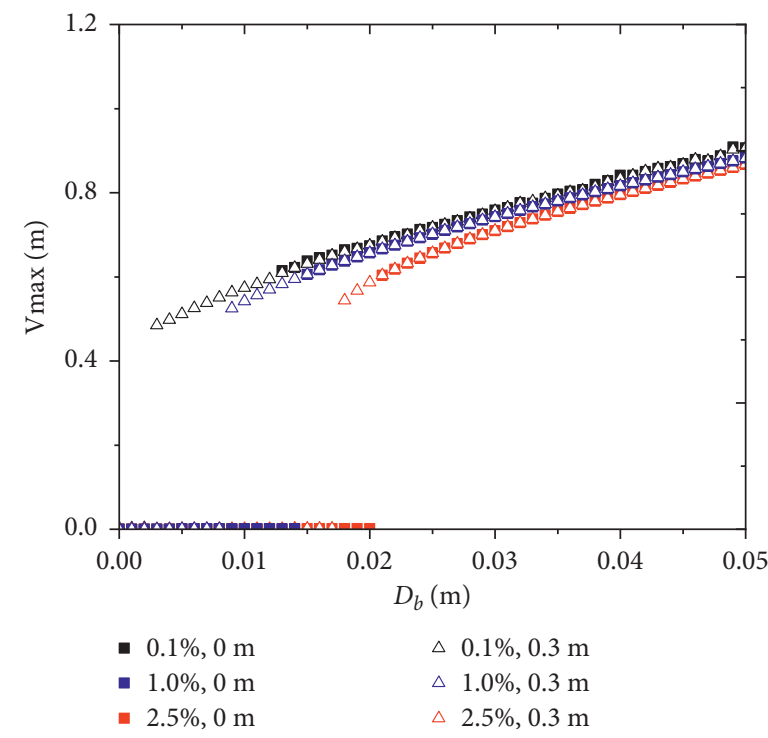

(c)

Figure 9: The peak amplitude at midspan of the cable with different excitation amplitudes and different damping ratios (working condition III). $0.1 \%, 0.5 \%, 1.0 \%$, and $2.5 \%$ are the damping ratios; $0 \mathrm{~m}$ and $0.3 \mathrm{~m}$ are the initial conditions. (a) $\omega_{b} / \omega_{1} \approx 0.502$. (b) $\omega_{b} / \omega_{1} \approx 1.04$. (c) $\omega_{b} /$ $\omega_{1} \approx 2.04$. 
However, for the case of $\omega_{b} / \omega_{1} \approx 2.04$, there are two Poincare section points in the phase plane diagrams, which is the nonlinear vibration characteristic of stayed cables excited by the ideal end harmonic displacement.

As shown in Figure 9, with the increase of the excitation amplitude at the end of cables, the vibration amplitude increases gradually, and there is a mutated point when the excitation amplitude approaches a certain critical value. This mutated phenomenon is one of the critical characteristics of nonlinear vibration of stayed cables. In addition, there are obviously two stable solutions near the mutation point and many unstable solutions between these two stable solutions. These unstable solutions can help us to better understand the vibration behaviors of the nonlinear system, such as the location and number of bifurcation points. Before the vibration amplitude increases suddenly, the vibration amplitude increases exponentially with increment of excitation amplitude when $\omega_{b} / \omega_{1} \approx 0.502$, and the vibration response increases linearly when $\omega_{b} / \omega_{1} \approx 1.04$. However, large-amplitude vibration may not occur unless the excitation amplitude exceeds a critical value when $\omega_{b} / \omega_{1} \approx 2.04$, which is significantly different from the first two resonance cases. In addition, once the excitation amplitude exceeds the critical value, the nonlinear vibration amplitude of the cable may be greater than that of the other two cases. In addition, the damping ratio has a limited effect on prohibiting the occurrence of large magnitude parameter vibrations of stayed cables, which is consistent with the results of the previous studies [11]. However, the damping ratio may increase the critical amplitude of support-displacement excitation that causes the large oscillation.

\section{Causes of Multiple Resonance Zones in Short Cable}

As mentioned above, there are five resonance zones for the short cable with a length of $30.6 \mathrm{~m}$. What is more, the fundamental frequency of the bridge deck is just close to $2 / 3$ of the fundamental frequency of the short cable. So, once the bridge deck vibrates under the wind or pedestrian excitation, this short cable may encounter with greater resonance excited by the vibration of the bridge deck. Therefore, it is necessary to deeply study the problem of multiple resonance zones for the short cable.

5.1. Characteristics of 2:3 Superharmonic Resonance. In order to explore the vibration characteristics of the cable at the $2: 3$ superharmonic resonance zone, the damping ratio was set to $0.1 \%$, and the vertical displacement excitation with the frequency of $2 / 3 \omega_{1}$ was applied to the beam end of the shortest cable, that is, $D_{b}=0.03 \sin \left(2 / 3 \omega_{1} t\right)$. The time history of displacement and the frequency spectrums at midspan of this short cable is shown in Figure 10.

As shown in Figure 10, a beat vibration phenomenon appears when the cable is excited by sinusoidal support displacement with frequency equals to $2 / 3 \omega_{1}$, and the phenomenon of beat vibration does not decay gradually with time. This beat vibration is mainly caused by the discrepancy between the exciting frequency and the inherent frequency of the cable itself. The steady displacement amplitude is about 15 times of the excitation amplitude, which will seriously affect the safety of the bridge. In addition, it can be found that the frequency spectrums of displacement at the middle span include multiple dominant frequencies. The components mainly include the excitation frequency $\omega_{b}$, the cable fundamental frequency $\omega_{1}$, the double frequency $2 \omega_{\mathrm{b}}$, $2 \omega_{1}$, the combined frequency of the excitation frequency, and the cable fundamental frequency: $\omega_{1}-\omega_{b}, \omega_{1}+\omega_{b}$, etc. Therefore, it is necessary to analyze the phenomenon of multiple resonance zones in short cables in detail and explore some effective control measures.

5.2. Effect of Cable Length. In order to analyze the phenomenon of multiple resonance zones when the frequency ratio is less than 1 , and whether the short cable has more resonance zones than the long cable, the cable length was varied to analyze the influence of the cable length on the resonance zones. The damping ratio was set to $0.1 \%$, the displacement excitation at the beam end was set to $D_{b}=0.03$ $\sin \left(\omega_{b} t\right)$. The peak amplitudes at midspan of the cable with different resonance zones and different lengths are plotted in Figure 11.

As shown in Figure 11, the shorter the cable length, the more the resonance zones appear in the low frequency ratio. For example, in contrast with the only two resonance zones in the low frequency ratio for the cable with $90 \mathrm{~m}$ in length, the cable resonates at frequency ratios $1: 3,1: 2$, and $2: 3$ for the cable with a length of $40 \mathrm{~m}$. The range of the primary harmonic resonance zone decreases with the decreasing cable length, while the range of the subharmonic and parametric resonance zones gradually increases, and this illustrates that the short cables are more likely to be induced the subharmonic and parametric resonances. However, it can be concluded from Figure 11 that the peak amplitude of the primary harmonic resonance decreases with decreasing cable length, and its variation is obviously greater than that of subharmonic and parametric resonances. The reason for this phenomenon is the influence of nonlinear factors in equation (2).

According to the above analysis, the cable does not have $2: 3$ superharmonic resonance when the length of the cable is greater than $77.5 \mathrm{~m}$, but the cable with a length of $50 \mathrm{~m}$ has a resonance vibration, and the amplitude of the $2: 3$ superharmonic resonance vibration increases with cable length decreasing. To better illustrate the existence of more resonance zones in the short cable, the frequency spectrums of cables' resonance displacement with different lengths at $2: 3$ frequency ratio were obtained and are shown in Figure 12.

It can be found that the dominant frequencies of the cable with length of $90 \mathrm{~m}$ includes six points, namely, $\omega_{b}, \omega_{1}$, $2 \omega_{b}, 2 \omega_{1}, \omega_{1}-\omega_{b}$, and $\omega_{1}+\omega_{b}$. However, the composition of the response frequency becomes more complex as the length of the cables decreases. When the cable length was reduced to $40 \mathrm{~m}$, the dominant frequencies increased to eleven. In addition, when the cable length is reduced from $90 \mathrm{~m}$ to $77.5 \mathrm{~m}$, with the exception of $\omega_{b}$, the amplitude of frequency 


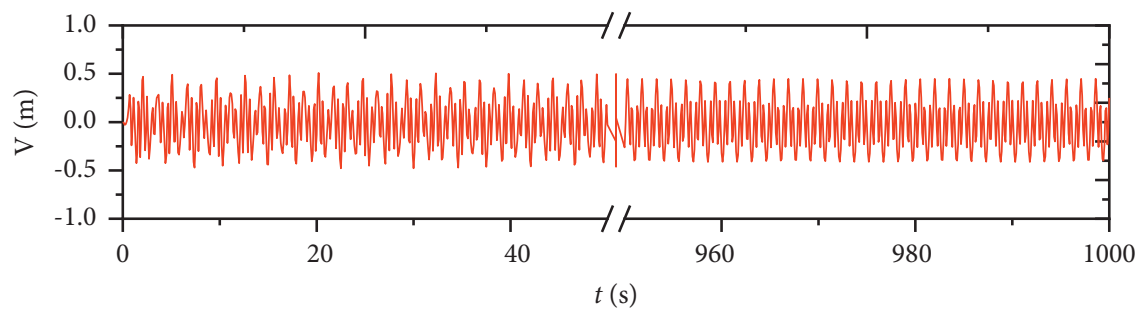

(a)

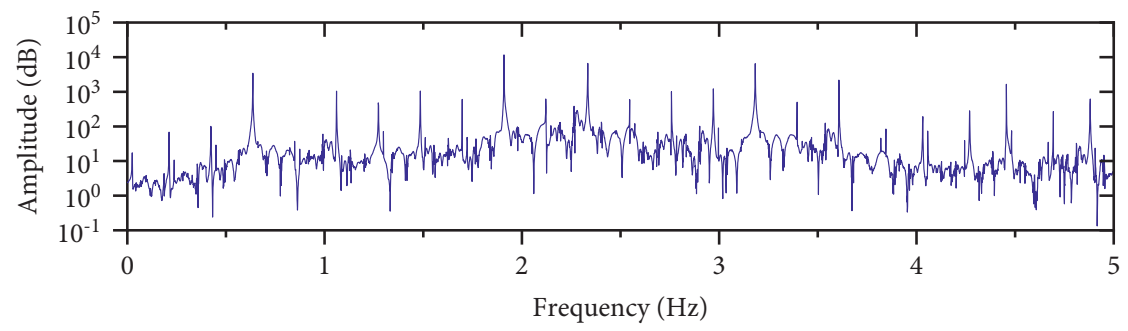

(b)

Figure 10: The time history of displacement (a) and the frequency spectrums (b) at midspan of the short cable.

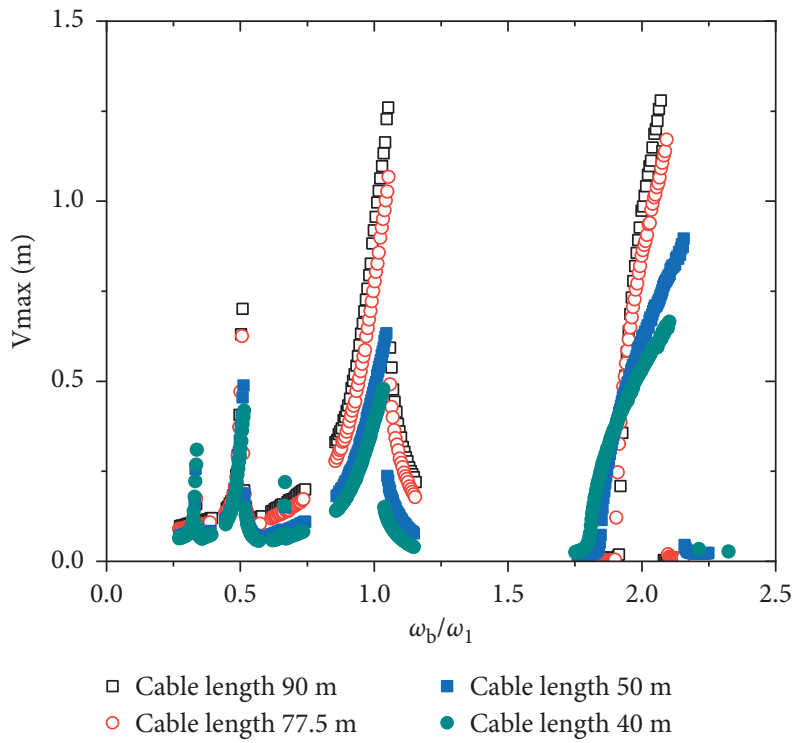

Figure 11: The peak amplitudes at midspan of the cable with different resonance zones and different lengths.

spectrum for each response frequency of the cable does not change much. However, when the cable length is reduced from $77.5 \mathrm{~m}$ to $50 \mathrm{~m}$, the amplitude of frequency spectrum for the fundamental frequency $\omega_{1}$ of the cable suddenly increases. The spectrum amplitude of excitation frequency $\omega_{b}$, followed by the double frequency $2 \omega_{b}, 2 \omega_{1}$, combined with frequency $\omega_{1}-\omega_{b}, \omega_{1}+\omega_{b}$, and some other combined frequency, also increases. When the cable length is no longer than $40 \mathrm{~m}$, the number of resonance points and their amplitudes in the frequency spectrum of the cable increase significantly, and the multifrequency excitation phenomenon becomes more obvious, resulting in a significant increment in the $2: 3$ superharmonic resonance amplitude. Through the above analysis, this can explain the reason why there are more resonance zones in short cables than in long cables. Under the same excitation amplitude condition, with the shorter cable length, the composition of the $2: 3$ superharmonic resonance response frequency gradually increases, and the amplitude of each response frequency also increases with the reduction of the cable length, thus causing the amplitude at the 2:3 superharmonic resonance of the short cable to increase significantly.

5.3. Effect of Excitation Amplitude. In order to investigate the effect of excitation amplitude on the multiple resonance zones of the cable, the vertical displacement excitation is applied at the end of the cable and altered the excitation amplitude to carry out analysis. The damping ratio is set to $0.1 \%$. The peak amplitudes at midspan of the cable with 


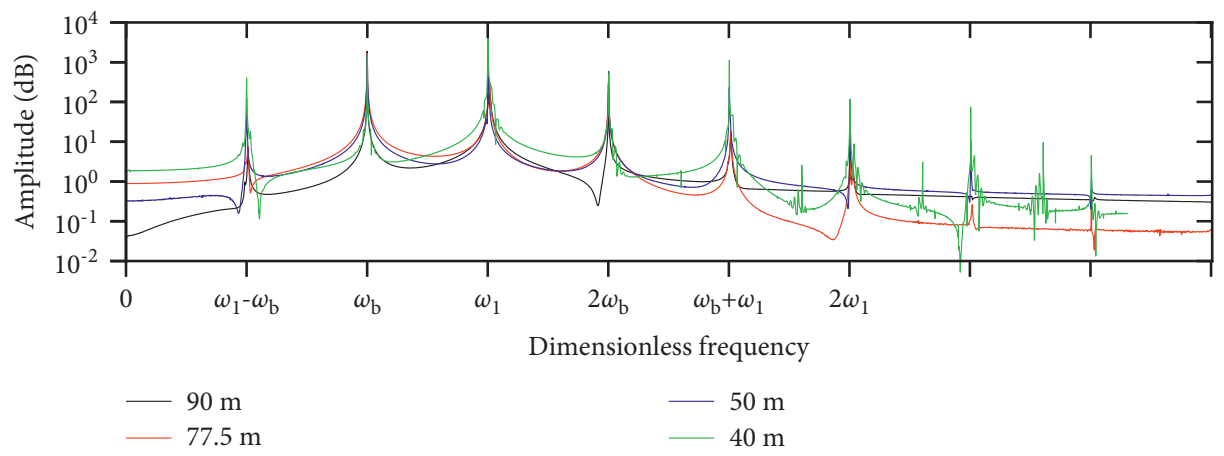

FIGURE 12: The frequency spectrums of different cable lengths $\left(\omega_{b} / \omega_{1}=2 / 3\right)$.

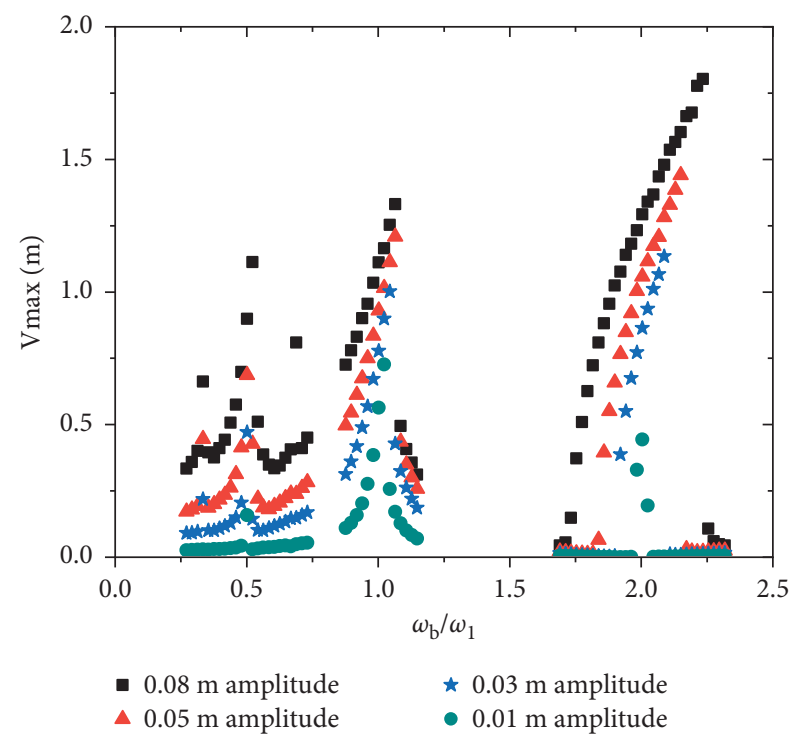

FIGURE 13: The peak amplitudes at midspan of the cable with different resonance zones and different excitation amplitudes.

different resonance zones and different excitation amplitudes are plotted in Figure 13.

It can be found from Figure 13 that the amplitudes of the subharmonic and parametric resonances are greatly affected by the excitation amplitude. When the excitation amplitude increases, the amplitudes of the subharmonic and parametric resonances increase significantly and are much larger than the excitation amplitude, so it is essential to suppress the vibration of deck and tower to control the subharmonic and parametric resonances of cables rather than increasing the damping ratio of cables. With the increase of the excitation amplitude, the resonant frequency ratio is gradually farther from 1.0 to 2.0, and more and more resonance zones in low frequency ratio area gradually increase. More specifically, the resonance zone at the frequency ratio of $1: 3$ appears once the excitation amplitude is beyond $0.01 \mathrm{~m}$, followed by the resonance zone at the frequency ratio of $2: 3$.

\section{Conclusions}

This paper takes a long cantilever bridge for a sightseeing platform as an example, and the dynamic model of the stayed cable is formulated with the essential boundary conditions at the ends of the cable. Then, the Galerkin method is adopted to establish the nonlinear parametric vibration equations of the stayed cables excited by the vibration of the bridge deck and tower. Then, the Runge-Kutta method solution processes are given in detail.

The dynamic response of stayed cables' nonlinear parametric vibration is obtained by the Runge-Kutta method, and the correctness and efficiency of the Runge-Kutta method has also been confirmed by comparing it with the finite element method under the same boundary conditions. The numerical analysis shows that subharmonic and parametric resonances require a certain critical value of excitation amplitude to produce large-amplitude vibration. Once the subharmonic and parametric resonances are excited, it is difficult to suppress them by increasing the damping ratio. However, it is effective and efficient to mitigate the nonlinear vibration by adjusting the frequency relationship between the whole structure and the cables. In addition, through the comparison of the vibration amplitude of the longest and shortest cables in the long cantilever bridge for the sightseeing platform, it is found that the length of the cables affects the number of resonance zones. The dominant frequencies and amplitude of the dynamic response increase significantly with shortening the cable length. However, excessive excitation amplitude at the end of the cable will also cause multiple resonance zones in the cable.

\section{Data Availability}

All data used to support the findings of this study are available from the corresponding author upon reasonable request.

\section{Conflicts of Interest}

The authors declare that there are no conflicts of interest regarding the publication of this paper.

\section{Acknowledgments}

This research was supported by the National Natural Science Foundation of China (51878106), the Natural Science Program of Chongqing (cstc2019jcyj-msxmX0818), the Science 
and Technology Research Program of Chongqing Municipal Education Commission (KJZD-K202100704), and the Joint Training Base Construction Project for Graduate Students in Chongqing (JDLHPYJD2020023). The authors greatly appreciate these financial supports.

\section{References}

[1] G. Rega, W. Lacarbonara, A. H. Nayfeh, and C. M. Chin, "Multiple resonances in suspended cables: direct versus reduced-order models," International Journal of Non-Linear Mechanics, vol. 34, no. 5, pp. 901-924, 1999.

[2] A. H. Nayfeh, H. N. Arafat, C.-M. Chin, and W. Lacarbonara, "Multimode interactions in suspended cables," Journal of Vibration and Control, vol. 8, no. 3, pp. 337-387, 2002.

[3] F. Benedettini, G. Rega, and R. Alaggio, "Non-linear oscillations of a four-degree-of-freedom model of a suspended cable under multiple internal resonance conditions," Journal of Sound and Vibration, vol. 182, no. 5, pp. 775-798, 1995.

[4] Y. Zhao, C. Huang, L. Chen, and J. Peng, "Nonlinear vibration behaviors of suspended cables under two-frequency excitation with temperature effects," Journal of Sound and Vibration, vol. 416, pp. 279-294, 2018.

[5] J. H. G. Macdonald, "Multi-modal vibration amplitudes of taut inclined cables due to direct and/or parametric excitation," Journal of Sound and Vibration, vol. 363, pp. 473-494, 2016.

[6] A. Gonzalez-Buelga, S. A. Neild, D. J. Wagg, and J. H. G. Macdonald, "Modal stability of inclined cables subjected to vertical support excitation," Journal of Sound and Vibration, vol. 318, no. 3, pp. 565-579, 2008.

[7] M. Demši'c, M. Uroš, A. J. Lazarevi, and D. Lazarević, "Resonance regions due to interaction of forced and parametric vibration of a parabolic cable," Journal of Sound and Vibration, vol. 447, pp. 78-104, 2019.

[8] Q. Wu, K. Takahashi, and S. Nakamura, "Formulae for frequencies and modes of in-plane vibrations of small-sag inclined cables," Journal of Sound and Vibration, vol. 279, no. 3-5, pp. 1155-1169, 2005.

[9] J. Peng, M. J. Xiang, L. H. Wang, X. Xie, H. Sun, and J. Yu, "Nonlinear primary resonance in vibration control of cablestayed beam with time delay feedback," Mechanical Systems and Signal Processing, vol. 137, Article ID 106488, 2020.

[10] T. Wang, R. L. Shen, and H. Li, "Primary exploration for concept and studying method of cable-beam vibration in a cable-stayed bridge," Journal of Vibration and Shock, vol. 32, no. 20 , pp. 29-34, 2013.

[11] F. Wang, X. X. Wen, and Z. J. Liu, "Coupled vibration analysis of tower-cable-deck of long-span cable-stayed bridge," Chinese Journal of Applied Mechanics, vol. 32, no. 2, pp. 340-346, 2015.

[12] Y. Y. Zhao and J. G. Lv, "Non-linear parametric vibration of cables in cable-arch composite structures," China Civil Engineering Journal, vol. 39, no. 12, pp. 67-72, 2006.

[13] J. G. Lv, Y. Y. Zhao, and R. H. Wang, "Nonlinear dynamics of cable-stayed arch under cables subjected to external excitation," Journal of Dynamics and Control, vol. 7, no. 1, pp. 14-18, 2009.

[14] G. Rega, N. Srinil, and R. Alaggio, "Experimental and numerical studies on inclined cables: free and parametricallyforced vibrations," Journal of Theoretical and Applied Mechanics, vol. 46, no. 3, pp. 621-640, 2008.

[15] C. Sun, Y. Zhao, J. Peng, H. Kang, and Y. Zhao, "Multiple internal resonances and modal interaction processes of a cable-stayed bridge physical model subjected to an invariant single-excitation," Engineering Structures, vol. 172, pp. 938955, 2018.

[16] J. Warminski, D. Zulli, G. Rega, and J. Latalski, "Revisited modelling and multimodal nonlinear oscillations of a sagged cable under support motion," Meccanica, vol. 51, no. 11, pp. 2541-2575, 2016.

[17] N. Srinil, G. Rega, and S. Chucheepsakul, "Two-to-one resonant multi-modal dynamics of horizontal/inclined cables. Part I: theoretical formulation and model validation," Nonlinear Dynamics, vol. 48, no. 3, pp. 231-252, 2007.

[18] T. D. Guo and G. Rega, "Modal dynamics of boundary-interior coupled structures. Part 1: a general approach using components Green's function," Mechanical Systems and Signal Processing, vol. 149, Article ID 107230, 2021.

[19] L. Wang and Y. Zhao, "Large amplitude motion mechanism and non-planar vibration character of stay cables subject to the support motions," Journal of Sound and Vibration, vol. 327, no. 1-2, pp. 121-133, 2009.

[20] F. C. Li, Parametric Vibration and cable Force Identification of Staying Cable of Large-Span Bridges, Harbin Institute of Technology, Harbin, China, 2010.

[21] D. G. Lei, J. J. Zheng, X. F. Liu, Z. P. Yu, and C. Y. Qi, “Fine derivation of the unified equation for three-dimensional vibration of stayed cable under end excitation," Journal of China Highway and Transport, vol. 32, no. 8, pp. 92-100, 2019.

[22] S. R. K. Nielsen and M. T. Sichani, "Stochastic and chaotic sub- and superharmonic response of shallow cables due to chord elongations," Probabilistic Engineering Mechanics, vol. 26, no. 1, pp. 44-53, 2011.

[23] E. De Sá Caetano, Cable Vibrations in Cable-Stayed Bridges, IABSE, Zürich, Switzerland, 2007. 